\title{
Tú y yo, y mi dolor: cuestión de personalidades
}

$\mathrm{E}$ 1 dolor crónico es uno de los ejemplos más claros de la compleja relación entre los componentes psicológicos, físicos y ambientales, de ahí la gran insistencia en la última década del abordaje multidisciplinar de esta problemática (1). Se ha planteado ya en numerosas ocasiones la importancia de tratar el dolor crónico no sólo de manera individual sino como parte del "set" familiar que lo acompaña, ya que se ha demostrado que el apoyo social es favorable en la percepción del dolor. Este objetivo ha sido plasmado en la plataforma "Societal Impact of Pain" de la European Pain Federation EFIC, donde se estableció una "Hoja de Ruta" para abordar el impacto social del dolor en Europa (ver: http://goo.gl/1SxjlW).

Llevar a la práctica estas consideraciones y ser capaz de plantear una intervención holística del paciente, además desde una perspectiva multidisciplinar, sin embargo, no parece tan sencillo. Abordar por sí solo al paciente, teniendo en cuenta los tres pilares sobre los que se sustenta: físico, psicológico y social, ya supone un gran reto por sí mismo, por lo tanto, plantearnos tener en cuenta a familiares y cónyuges, podría complicar aún más las cosas.

Cada familia supone un gran sistema; un complejo engranaje de ruedas dentadas que posee una inercia establecida tras el paso de los años. Un conjunto de miembros donde cada uno aporta sus rasgos de personalidad y constituye un rol dentro de dicho sistema.

Algunos ejemplos del dinamismo de estos roles se han observado en cónyuges de aquellos que sufren dolor aquejados por la incertidumbre respecto al estado de su pareja. Incertidumbre que a menudo va acompañada de desesperanza e impotencia. Dado este caldo de cultivo emocional no es de extrañar que surjan conflictos entre el acercamiento y la evitación hacia la pareja que sufre, especialmente por parte de los cónyuges de pacientes con altos niveles de dolor e ira. Estos familiares evitan en gran medida interaccionar con el doliente para no tener que sufrir las respuestas hostiles, una conducta que tiene como resultado mayor sentimiento de culpa e impotencia, y mayor riesgo de depresión $(2,3)$. También han sido descritas las ganancias secundarias en el paciente con dolor, derivadas de la exhibición de la conducta dolorosa (4). Los beneficios que se pueden obtener tienen que ver con mayor atención y amabilidad por parte de los familiares, amigos y personal sanitario, evitación de situaciones desagradables, o de realizar determinadas actividades. Es decir, conductas relacionadas con la queja y el refuerzo positivo de la misma por parte de los demás, que aumentan la probabilidad de que la conducta dolorosa se repita.

Diversos modelos teóricos han tratado de dar explicación a estas dinámicas: los sistemas familiares, el condicionamiento operante o los modelos transaccionales (5). Todos ellos señalan los efectos de la dinámica familiar en el inicio y/o perpetuación de los problemas de dolor, y sostienen que algunas de ellas representan una variedad de la familia psicosomática. Se han descrito cuatro características atribuidas a familias psicosomáticas, también observadas en muchas familias que conviven con el dolor crónico: a) enmarañamiento con los límites del yo débiles entre miembros de la familia; b) sobreprotección con el comportamiento excesivamente solícito hacia los demás; c) rigidez con roles y reglas inflexibles; y d) escaso reconocimiento o falta de habilidades para la resolución de conflictos (6). 
Precisamente un acercamiento a este marco teórico es lo que nos encontraremos en este número de la Revista de la Sociedad Española del Dolor en un estudio firmado por Collazo y cols. (7). Tal y como exponen en su artículo, la investigación surge a raíz de la detección de un determinado modo de actuación entre los cónyuges de pacientes con dolor, y la pregunta que se plantean es sencilla: ¿existe un determinado tipo de personalidad en estos cónyuges? Sin duda un gran reto el que afrontan estos investigadores y, sobre todo, un punto de partida interesante para abordar una parte importante del paciente con dolor. Estudiar los rasgos de personalidad implicará establecer un modelo explicativo del comportamiento humano que desvelará características estables y consistentes que determinan, explican y permiten predecir el comportamiento individual en la medida en que guían la forma en que cada individuo piensa e interpreta la realidad. Esto es, sin duda, un recurso valioso en este contexto del dolor crónico del que poder sacar beneficios. Como bien concluyen Collazo y cols. el fin es intentar evitar el deterioro de la convivencia familiar de estos pacientes, ya que esto siempre irá a favor del tratamiento y la mejora de la calidad de vida del paciente y su entorno.

Por ello, implicar a la familia, especialmente a los cónyuges, en el control del dolor supone apoyar y acompañar a la familia en el proceso de comprensión de sus propios repertorios y dinámicas conductuales y de comunicación, animando la generación conjunta de vías de solución y de cambio que permitan el (re)establecimiento de una vida familiar sana, respetuosa y desprovista de temores. No se trata de la prescripción de la "felicidad" de acuerdo con una determinada receta, sino más bien se trata de la mutua aceptación en pos del bien común.

B. Ojeda Ballesteros

Universidad de Cádiz

\section{BIBLIOGRAFÍA}

1. Goldberg DS, McGee SJ. Pain as a global public health priority. BMC Public Health 2011;11:770. doi:10.1186/1471-2458-11-770.

2. Closs SJ, Staples V, Reid I, Bennett MI, Briggs M. The impact of neuropathic pain on relationships. Journal of Advanced Nursing 2009;65(2):402-11. doi:10.1111/j.1365-2648.2008.04892.x.

3. Strunin L, Boden LI. Family consequences of chronic back pain. Social Science and Medicine 2004;58(7):1385-93. doi:10.1016/S0277-9536(03)00333-2.

4. Fordyce WE, Fowler RS, Jr, Lehmann JF, Delateur BJ, Sand PL, Trieschmann RB. Operant conditioning in the treatment of chronic pain. Archives of Physical Medicine and Rehabilitation 1973;54(9):399-408.

5. Lewandowski W, Morris R, Draucker CB, Risko J. Chronic pain and the family: Theory-driven treatment approaches. Issues in Mental Health Nursing 2007;28(9): 1019-44. doi:10.1080/01612840701522200.

6. Kerns RD, Otis JD. Family therapy for persons experiencing pain: Evidence for its effectiveness. Seminars in Pain Medicine 2003;1(2):79-89. doi:10.1016/S1537-5897(03)00007-7.

7. Collazo E, Aragonés MA, Muñoz D. Trastornos de personalidad en los cónyuges de pacientes con dolor crónico. Rev Soc Esp Dolor 2014;21(5):235-41. 